\title{
The Effect of Selected Combretum Species from Zimbabwe on the Growth and Drug Efflux Systems of Mycobacterium aurum and Mycobacterium smegmatis
}

\author{
Ruvimbo Magwenzi, Colet Nyakunu and Stanley Mukanganyama*
}

Department of Biochemistry, University of Zimbabwe, Mt. Pleasant, Harare, Zimbabwe

\begin{abstract}
Treatment of tuberculosis has become a challenge due to the rapid increase of multidrug and extensive drug resistant Mycobacterium tuberculosis. Medicinal plants might represent a possible source for new potent antibacterials to which pathogen strains are not resistant. In this study, five Combretum plant species-Combretum imberbe, Combretum zeyheri, Combretum hereroense, Combretum elaeagnoides and Combretum platypetalum used in traditional medicine were exposed to susceptibility tests to determine the effects of drug accumulation in avirulent $M$. smegmatis and $M$. aurum. The MIC values of the potent plant species was then determined. Using the agar disc diffusion assay, it was found out that the only the ethanolic extract from Combretum imberbe was active on M. smegmatis and it had an MIC of $125 \mu \mathrm{g} / \mathrm{ml}$ in the broth microdilution assay. However, using Sabouraud dextrose broth, Combretum platypetalum was found to have antimycobacterial effects which were not detected when using the agar disc diffusion assay. MIC of 63 and $125 \mu \mathrm{g} / \mathrm{ml}$ and MBCs of 250 and $500 \mu \mathrm{g} / \mathrm{ml}$ were obtained for $C$. platypetalum for $M$. smegmatis and $M$. aurum respectively. C. imberbe extract gave an MIC of $125 \mu \mathrm{g} / \mathrm{ml}$ but did not produce MBCs suggesting that it is bacteriostatic and not bactericidal. Drug accumulation transport assays were performed on $C$. imberbe, $C$. hereroense and $C$. platypetalum and results show that extracts from two plants are efflux pump inhibitors. Determination of the IC50 for the transport process was as conducted on Combretum imberbe using CCCP as the standard inhibitor. Both plants extract in addition to $C$. hereroense maybe potential sources for leads for efflux pump inhibitor in mycobacteria.
\end{abstract}

Keywords: Tuberculosis; Mycobacteria; Combretum species; Antituberculosis; Drug efflux

\section{Introduction}

Tuberculosis (TB) has threatened humanity for thousands of years and remains one of the deadliest diseases on planet earth [1]. It is the leading cause of death worldwide from a single pathogen, claiming more lives than AIDS, malaria, diarrhea, leprosy, and all other tropical diseases combined [2]. TB is believed to be largely a disease of poverty, with the highest incidences occurring in Asia and Africa [3]. The increase in TB incidence in Africa is strongly associated with the prevalence of HIV infection among TB patients, exceeding $60 \%$ in South Africa, Botswana, Zambia, and Zimbabwe [4]. Zimbabwe is ranked 16th on the list of 22 high burden TB countries in the world. It has indicated that Zimbabwe had 71,961 tuberculosis cases in 2007 and an estimated incidence rate of 540 cases per 100,000 populations [5]. Human tuberculosis (TB) is mainly caused by Mycobacterium tuberculosis. The mycobacterium is aerobic, pathogenic and usually establishes its infection in the lungs [2].

Treatment of TB requires multi-drug therapy comprising; an initial intensive phase of rifampicin, isoniazid, pyrazinamide, and ethambutol daily for two months and a continuation phase of rifampicin and isoniazid for a further 4 months, either daily or 3 times a week. Isoniazid and ethambutol, eradicate most of the rapidly replicating bacilli in the first 2 weeks of treatment. Thereafter, rifampicin and pyrazinamide have an important role in the sterilization of lesions by eradicating organisms; these two drugs are crucial for the successful 6-month treatment regimens. Rifampicin and isoniazid are the main drugs used today, rifampicin being the more important agent in terms of reducing the duration of treatment and assuring favorable outcomes. However, these drugs are being rendered useless because of the emergence of drug-resistant $\mathrm{TB}$, such as multi-drug resistant $\mathrm{TB}$ (MDR-TB) and extensively drug-resistant TB (XDR-TB) and this has contributed to the resurgence of tuberculosis [6]. Resistance decreases the effectiveness of most available antitubercular agents, and therefore, there is an urgent need to develop new drugs to help reduce the global burden of tuberculosis [6].

Plants comprise the largest component of the diverse therapeutic elements of traditional health care practices in both humans and animals. Plants are rich in a wide variety of secondary metabolites, such as tannins, terpenoids, alkaloids, and flavonoids, which have been found in vitro to have antimicrobial properties [7]. A number of interesting outcomes have been found with the use of a mixture of natural products to treat diseases, most notably the synergistic effects and polypharmacological application of plant extracts [8]. Since the advent of antibiotics, in the 1950s, the use of plant derivatives as antimicrobials has been virtually nonexistent. The interest in using plant extracts for treatment of microbial infections has increased in the late 1990s, as conventional antibiotics become ineffective [7]. Antimicrobial compounds from plants may inhibit bacteria/fungi through different mechanisms than conventional antibiotics, and could therefore be of clinical value in the treatment of resistant microbes [9]. Natural

*Corresponding author: Dr. Stanley Mukanganyama, Biomolecular Interactions Analyses Group, Department of Biochemistry, University of Zimbabwe, P.O. Box MP 167, Mt. Pleasant Harare, Zimbabwe, Tel: 263-4-2917638/09; E-mail: smukanganyama@medic.uz.ac.zW, smukanganyama01@gmail.com

Received April 15, 2014; Accepted May 07, 2014; Published May 14, 2014

Citation: Magwenzi R, Nyakunu C, Mukanganyama S (2014) The Effect of Selected Combretum Species from Zimbabwe on the Growth and Drug Efflux Systems of Mycobacterium aurum and Mycobacterium smegmatis. J Microbial Biochem Technol S3: 003. doi:10.4172/1948-5948.S3-003

Copyright: (c) 2014 Magwenzi R, et al. This is an open-access article distributed under the terms of the Creative Commons Attribution License, which permits unrestricted use, distribution, and reproduction in any medium, provided the original author and source are credited 
Citation: Magwenzi R, Nyakunu C, Mukanganyama S (2014) The Effect of Selected Combretum Species from Zimbabwe on the Growth and Drug Efflux Systems of Mycobacterium aurum and Mycobacterium smegmatis. J Microbial Biochem Technol S3: 003. doi:10.4172/1948-5948. S3-003

Page 2 of 7

products continue to play a most significant role in the drug discovery and development process, and plants are recognized as a useful source of highly active antimycobacterial metabolites [10]. Antimicrobial resistance in medicine is now recognized as a major emerging problem of public health importance [11]. The search and development of new, more efficient and safe antimycobacterial drugs is warranted. At least twenty four species of Combretum are well known in African traditional medicine and are used for the treatment of a variety of ailments and diseases, ranging from scorpion and snake bites, mental problems, heart and worm remedies to fever and microbial infections. The wide spread use of Combretum species in treatment of TB related symptoms and other ailments makes them potential sources of lead compounds that can be developed as antitubercular drugs. Many species of Combretum have been found to possess powerful antibacterial and antifungal effects. The large number of antimicrobial compounds found in species of Combretum might explain why they are so widely used in African traditional medicine. Among antimicrobial active compounds isolated from Combretum species are combretastatins (bibenzyle compounds), acidic tetracyclic and pentacyclic triterpenes/ triterpenoids, ellagitannins, phenanthrenes, flavonoids, saponins and cycloartane glycosides [12]. The leaves, roots and stem bark of $C$. zeyheri are used medicinally. The leaves are used frequently and have a variety of uses in African traditional medicine. The smoke of burnt leaves is inhaled for treatment of coughs. The leaves of C. imberbe are used in the treatment of diarrhea and cough, symptoms that can be related to bacterial and fungal infection.

The study was undertaken to test the antimycobacterial activity of the five Combretum plant species from Zimbabwe against M. smegmatis and M. aurum, model organisms for Mycobacterium tuberculosis.

\section{Materials and Methods}

\section{Materials}

All the chemicals used were obtained were obtained from Sigma Aldrich (Darmstadt, Germany). The list included the culturing media, Middlebrook 7H9 that was supplemented with casein acid hydrosylate and agar select that was used for preparing solid bacterial media. Absolute ethanol was used in preparing plant extracts. Rifampicin and 3-(4, 5-dimethylthiazol-2-yl)-2, 5-diphenyltetrazolium bromide (MTT) were used in the antimycobacterial susceptibility tests. Sodium dihydrogen phosphate and disodium hydrogen phosphate, glycine, hydrochloric acid 2-[(3-chlorophenyl) hydrazinylidene] propane CCCP, ciprofloxacin and dimethyl sulphoxide (DMSO) was also used in the assays. Other chemicals used were of the highest grade available and were obtained from different sources. The organisms used as model bacteria for Mycobacterium tuberculosis, Mycobacterium aurum $(\mathrm{A}+)$ and Mycobacterium smegmatis mc2155, were obtained were obtained from Prof. Smith of the Department of Pharmacology, University of Cape Town and Prof. Steenkamp, of the Department of Clinical Laboratory studies (University of Cape Town).

\section{Plant collection preparation of extracts}

Plants used in this study, Combretum imberbe, Combretum elaeagnoides, Combretum hereroense, and Combretum zeyheri, were obtained from the National Botanical Gardens in Harare, Zimbabwe. Combretum platypetalum was obtained from Norton, Mashonaland West Province of Zimbabwe. A taxonomist from there, Mr. Christopher Chapano, authenticated their identity. The voucher specimens of the plants investigated, BOT 2 E7 for $C$. elaeagnoides, BOT E7 for $C$. zeyheri BOT 9 for C. hereroense, BOT $10 \mathrm{E} 7$ for C. imberbe, and BOT 11
E7 for C. platypetalum were kept in the Department of Biochemistry, University of Zimbabwe. The plant leaves were oven dried at $50^{\circ} \mathrm{C}$ and ground to a fine powder in a two-speed electric blender. A volume of 8 $\mathrm{ml}$ of ethanol was added to two grams of the powder and the mixture was shaken in a vortex mixer for 5 minutes. The mixture was left to sit for an hour and was then filtered using a syringe that had a piece of cloth inserted in it and sterilization of the suspension was done by using a millipore $45 \mu \mathrm{m}$ sterile filter and $2 \mathrm{ml}$ syringe into a labeled small glass vial. The solvent was evaporated under a stream of air in a fume cupboard at room temperature to quantify the extraction. The extract was then dissolved in absolute ethanol for use.

\section{Growth of bacteria}

Middlebrook 7H9 media was made up with $5.2 \mathrm{~g} / \mathrm{L}$ Middlebrook 7H9 base supplemented with $1 \mathrm{~g} / \mathrm{L}$ casein hydrosylate $(\mathrm{CAH})$ was used for the growth of mycobacteria. The media components were dissolved in 1 liter of boiled distilled water and autoclaved to sterilize them. Mycobacterium aurum and Mycobacterium smegmatis were grown in Middlebrook 7H9 media supplemented with casein acid hydrosylate and in Middlebrook $7 \mathrm{H} 9$ solid media at $37^{\circ} \mathrm{C}$ under aerobic conditions.

\section{Determination of antimycobacterial activity}

To determine the activity of the plant extracts as antimycobacterials, initial screening was carried out using the agar disc diffusion method [13]. Once identified as being potent, growth inhibition parameters were determined using the broth microdilution method. The method used was modified from that of [13]. The test material equivalent to $500 \mu \mathrm{g}$, dissolved in ethanol was applied to sterile paper discs $(6 \mathrm{~mm}$ diameter, cartridge susceptibility discs, Mast Diagnostics, Mast Group Ltd, Merseyside, UK). The solvent was allowed to evaporate at room temperature from filters on 96-well plates. The discs were placed in microtitre plates and loaded with the various plant extracts. Rifampicin was used as a positive control at final concentrations of 50, 5, 0.5, and $0.1 \mu \mathrm{l} / \mathrm{ml}$ with DMSO as the negative control. The filters papers with the loaded compounds were dried under an air stream. A $1 \times 10^{6}$ colony forming units $(\mathrm{cfu}) / \mathrm{ml}$ of mycobacteria was mixed with Middlebrook 7H9 agar. The mixture was poured and spread onto plates. The dried filter paper discs were placed on the surface of the solid agar and incubated at $4^{\circ} \mathrm{C}$ in a refrigerator for two hours to allow diffusion of compounds into the agar. The plates were removed from the refrigerator and incubated at $37^{\circ} \mathrm{C}$ overnight in an incubating shaker (Jeio Tech, Korea). The zone of inhibition around each of the discs was measured in $\mathrm{mm}$ and indicated the activity of the plant extract against the mycobacterial organism. The assay was done in duplicate and repeated four times.

Plant extracts that did not show activity against the mycobacterial organisms using the agar disc diffusion were further investigated using the broth microdilution method. This was to evaluate whether agar diffusion effects had resulted in inactivity. The results then obtained from the two antimycobacterial susceptibility tests were compared. Comparison of the two methods was to evaluate the sensitivity levels of each individual method and, thus, deduce the better one for future use.

\section{Determination of MICs and MBCs}

The plant extract showing activity against the mycobacteria species was then used in the broth microdilution assay to determine its minimal inhibition concentration (MIC) and its minimal bactericidal concentration (MBC) [3]. The plant extract was serially diluted from $50 \mu \mathrm{g} / \mathrm{ml}$ with DMSO up to a concentration of $0.1 \mu \mathrm{g} / \mathrm{ml}$. Aliquots 
Citation: Magwenzi R, Nyakunu C, Mukanganyama S (2014) The Effect of Selected Combretum Species from Zimbabwe on the Growth and Drug Efflux Systems of Mycobacterium aurum and Mycobacterium smegmatis. J Microbial Biochem Technol S3: 003. doi:10.4172/1948-5948. S3-003

Page 3 of 7

of $20 \mu \mathrm{l}$ of the above compound were taken and added to $80 \mu \mathrm{l}$ of X2 Middlebrook 7H9 supplemented with casein acid hydrolysate medium in wells of a 96 well microtitre plate in duplicate. Two rows of the serially diluted compound were left with no inoculum. Rifampicin was used as the positive control, and was serially diluted from a concentration of $50 \mu \mathrm{g} / \mathrm{ml}$ to $0.1 \mu \mathrm{g} / \mathrm{ml}$. Mycobacterium species was added to each of the wells in $100 \mu \mathrm{l}$ aliquots with the exception of the sterility control wells where only media was added. The microplate were covered and sealed with parafilm before being placed in a plastic container lined with absorbent paper saturated with sterile water. The container was wrapped in aluminum foil and incubated at $37^{\circ} \mathrm{C}$ overnight in an incubating shaker (Jeio Tech, Korea). Aliquots of $40 \mu \mathrm{l}$ of MTT were added to all the wells and the plate was incubated at $37^{\circ} \mathrm{C}$ for 1 hour. The optical densities of the wells were read using Biokinetics Reader EL350 (Bio-Tek TM Instruments, Highlands Park, Winooski, VT, USA) at $550 \mathrm{~nm}$. The wells that did not show any color change after MTT was added indicated the concentration of the plant extract that was able to inhibit mycobacterium growth whereas the purple color change indicated mycobacterium growth. The MBCs of the compound were determined on solid Middlebrook media 7H9 media. Aliquots were taken from wells that had no visible growth including both the controls and streaked onto solid agar using a sterile loop. The plates are then incubated overnight and checked for growth to determine the $\mathrm{MBC}$ of each compound.

\section{Ciprofloxacin accumulation assay}

To determine the effect of plant extracts on mycobacterium efflux pumps, accumulation of ciprofloxacin was measured by the method of Michot et al. [14] with modifications. Mycobacteria were grown in Middlebrook $7 \mathrm{H} 9$ at $37^{\circ} \mathrm{C}$ to OD600 of between $0.5-0.7$ and harvested by centrifugation at $3000 \mathrm{rpm}$ for 5 minutes. Mycobacteria were then washed once with $50 \mathrm{mM}$ sodium phosphate buffer $\left(\mathrm{pH} \mathrm{7.0)}\right.$ at $4^{\circ} \mathrm{C}$ and made up to $40 \mathrm{mg} / \mathrm{ml}$ (dry weight of cells). The cells were placed in a water bath set at $37^{\circ} \mathrm{C}$ for 15 minutes. Cells were then split into sample $\mathrm{A}$ and $\mathrm{B}$ and maintained at the same temperature. Ciprofloxacin was then added to both samples to a final concentration of $20 \mathrm{mg} / \mathrm{L}$. Aliquots of $750 \mu \mathrm{l}$ were taken at $0,1,5,10,15,30,45$ and 60 minutes after the addition of ciprofloxacin from both sample A and B. Samples were diluted immediately into $750 \mu \mathrm{l}$ chilled sodium phosphate buffer ( $\mathrm{pH} 7.0)$ on ice, and then centrifuged in a micro centrifuge (Hermle Labortechnik, Germany) at $8000 \mathrm{rpm}$ at $4^{\circ} \mathrm{C}$ for 5 minutes. The cells were then washed with chilled phosphate buffer and centrifuged for 5 minutes. The cell pellet was suspended in $1.5 \mathrm{ml}$ glycine hydrochloride $(0.1 \mathrm{~mol} / \mathrm{L}, \mathrm{pH} 3.0)$ for 2 hours at $37^{\circ} \mathrm{C}$ and centrifuged at $8000 \mathrm{rpm}$ for 10 minutes. The supernatant was centrifuged for another 5 minutes.
The active efflux of ciprofloxacin was determined at the excitation and emission wavelengths of $270 \mathrm{~nm}$ and $452 \mathrm{~nm}$ respectively using an RF1501 Shimadzu spectrofluorimeter (Shimadzu Corporation, Japan). The active efflux of ciprofloxacin was examined as well in the presence of CCCP, a standard drug efflux pump inhibitor.

\section{Statistical analysis}

Data analyses were performed using GraphPad Instat software (GraphPad Prism Inc. San Diego, CA, USA). Levels of significance were determined using ANOVA using the Dunnet posttest where all columns of treatments were compared to the control. All data were expressed as mean \pm standard deviation. $\mathrm{P} \leq 0.05$ values or less were considered to indicate statistically significant difference.

\section{Results}

\section{Antimycobacterial activity of plant extracts}

Amongst the five plant extracts tested, Combretum imberbe was the only one to show activity against Mycobacterium smegmatis with a zone of inhibition of $9.5 \mathrm{~mm}$. None of the plant extracts were active against Mycobacterium aurum in this assay. Rifampicin was used as the positive control while DMSO was the negative control. The greatest zones of inhibition were observed with rifampicin, the standard drug, with $50 \mu \mathrm{g} /$ disc of rifampicin giving zones of $33 \mathrm{~mm}$ and $21.75 \mathrm{~mm}$ for $M$. smegmatis and $M$. aurum respectively (Table 1 ). The five Combretum species plant extracts were not active against $M$. aurum using the agar disc diffusion. However using the broth test, $C$. platypetalum showed activity against both $M$. smegmatis and M. aurum (Figure 1). Further tests were performed using the broth microdilution method to determine the MIC.

\section{MIC and MBC determination}

In order to quantify the activity of Combretum platypetalum and Combretum imberbe, the only two plant extracts that showed activity against $M$. smegmatis and $M$. aurum, the broth microdilution assay was used in order to determine the minimum inhibitory concentration. Varying concentrations of the plant extract were tested, and these ranged from $1000 \mu \mathrm{g} / \mathrm{ml}$ to $0.48 \mu \mathrm{g} / \mathrm{ml}$. The MIC of rifampicin was calculated as well, and concentrations of between $50 \mu \mathrm{g} / \mathrm{ml}$ and $0.01 \mu \mathrm{g} / \mathrm{ml}$ were used. Combretum imberbe had an MIC of $125 \mu \mathrm{g} / \mathrm{ml}$ and this was not comparable to that of rifampicin, which was $0.2 \mu \mathrm{g} /$ $\mathrm{ml}$ (Table 1). MICs of 63 and $125 \mu \mathrm{g} / \mathrm{ml}$ and MBCs of 250 and 500 $\mu \mathrm{g} / \mathrm{ml}$ were obtained for $C$. platypetalum for $M$. smegmatis and $M$. aurum respectively. Combretum imberbe did not show an $\mathrm{MBC}$ at the

\begin{tabular}{|l|l|l|}
\hline Combretum species & Vernacular name and English name & Ethnomedicinal Use \\
\hline $\begin{array}{l}\text { Combretum hereroense Schinz } \\
\text { subsp. hereroense }\end{array}$ & $\begin{array}{l}\text { Ithetshane (Ndebele) Mouse-eared Combretum (English) } \\
\text { Murovamhuru (Shona) Mutechani (Shona) Russet } \\
\text { bushwillow (English) }\end{array}$ & Bilharzias, headache, infertility in women \\
\hline Combretum imberbe Wawra & $\begin{array}{l}\text { Leadwood (English), Monzo (Shona), Muchenarota } \\
\text { (Shona), Mutsviri (Shona), }\end{array}$ & Coughs. Colds, diarrhoea \\
\hline $\begin{array}{l}\text { Combretum platypetalum Welw. ex M.A. Lawson } \\
\text { subsp. oatesii (Rolfe) Exell }\end{array}$ & $\begin{array}{l}\text { Bepu (Shona) Dwarf red Combretum (English) Red wings } \\
\text { (English) Redwings (English) }\end{array}$ & $\begin{array}{l}\text { Swelling caused by mumps, pneumonia, abdominal } \\
\text { pains, diarrhoea, antiemetic, dysmenorrhoea, infertility } \\
\text { in women, earache, epistaxis, haeophysis }\end{array}$ \\
\hline Combretum zeyheri Sond & $\begin{array}{l}\text { Large-fruited bushwillow (English) Muchenja (Shona) } \\
\text { Mupembere-kono (Shona) Muruka (Shona) Umbhondo } \\
\text { (Ndebele) Umbula (Ndebele) }\end{array}$ & $\begin{array}{l}\text { Toothaches, cough, scorpion bite, bloody diarrhoea, } \\
\text { arrest mensual flow, eye lotion, embrocation, abdominal } \\
\text { disorders. }\end{array}$ \\
\hline Combretum elaeagnoides Klotzsch & $\begin{array}{l}\text { Large-fruited jesse-bush Combretum (English), Oleaster } \\
\text { bushwillow (English), Muswati (Shona), Mukalanga, } \\
\text { Mugupa (Ndebele), Mukapo (Shona) }\end{array}$ & Antifungal, malaria \\
\hline
\end{tabular}

Table 1: Traditional medical uses of Combretaceae species used in this study. 
Citation: Magwenzi R, Nyakunu C, Mukanganyama S (2014) The Effect of Selected Combretum Species from Zimbabwe on the Growth and Drug Efflux Systems of Mycobacterium aurum and Mycobacterium smegmatis. J Microbial Biochem Technol S3: 003. doi:10.4172/1948-5948. S3-003

Page 4 of 7

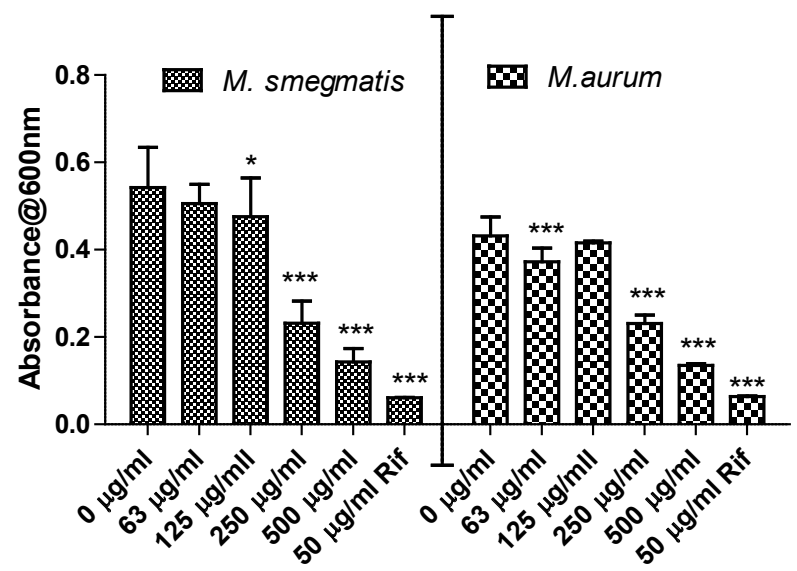

\section{Concentration of extract (or rifampicin)}

Figure 1: The effects of $C$. platypetalum on the growth of mycobacteria in broth $M$. smegmatis and $M$. aurum were grown in broth and exposed to increasing concentrations of $C$. platypetalum leaf extracts in a 96-well microplate. Values are the mean of $+S D$ for $n=16$ for duplicate measurements ${ }^{* *} \mathrm{P}<0.0001$, ${ }^{* *} \mathrm{P}<0.001{ }^{*} \mathrm{P}<0.05$
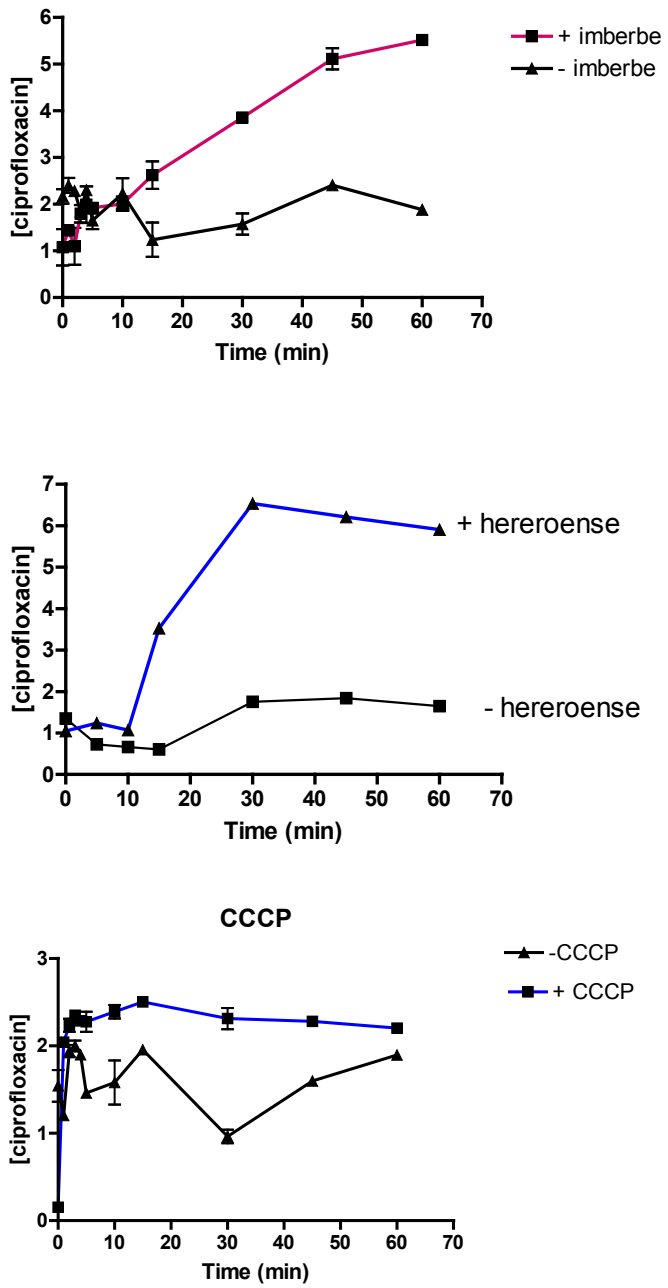

Figure 2: Graph of ciprofloxacin accumulation in $M$. smegmatis in the presence of Combretum imberbe. (Values are means $\pm \mathrm{SD} N=2$ ). concentrations that were tested, suggesting that it was bacteriostatic. The MBC of rifampicin was $50 \mu \mathrm{g} / \mathrm{ml}$.

\section{Effect of plant extracts on Mycobacterium smegmatis efflux pumps}

The effect of Combretum imberbe on Mycobacterium smegmatis was determined using the ciprofloxacin drug accumulation assay. The effect of Combretum hereroense plant extract on the mycobacterial efflux pumps was investigated as well, even though the plant extract did not show any activity in the agar disc diffusion assay. This was to test if an extract that did not have antimycobacterial effects could have efflux pumping inhibitory activity. Active accumulation of ciprofloxacin in Mycobacterium smegmatis was monitored in the presence and absence of the plant extracts, and for comparisons, accumulation of ciprofloxacin was monitored in the presence of CCCP, a known efflux pump inhibitor. End point monitoring of the accumulation of ciprofloxacin was carried out for C. platypetalum for both $M$. smegmatis and $M$. aurum. Graphs showing the accumulations of ciprofloxacin with time were plotted (Figures 2-4). The ciprofloxacin concentration was

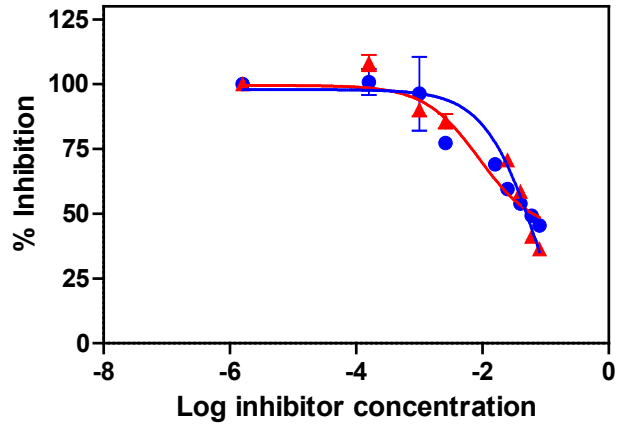

- C imberbe

$\triangle \mathrm{CCCP}$

Figure 3: The effect of increasing CCCP and $C$. emberbe extract on the efflux of ciprofloxacin from $M$. smegmatis. The compounds were added at various concentrations to the cells. The cells were then centrifuged and the amount ciprofloxacin in the supernatant quantified at excitation and emission wavelengths of $270 \mathrm{~nm}$ and $452 \mathrm{~nm}$ respectively using an RF-1501 Shimadzu spectrofluorimeter. Values are means + SD for duplicate measurements.

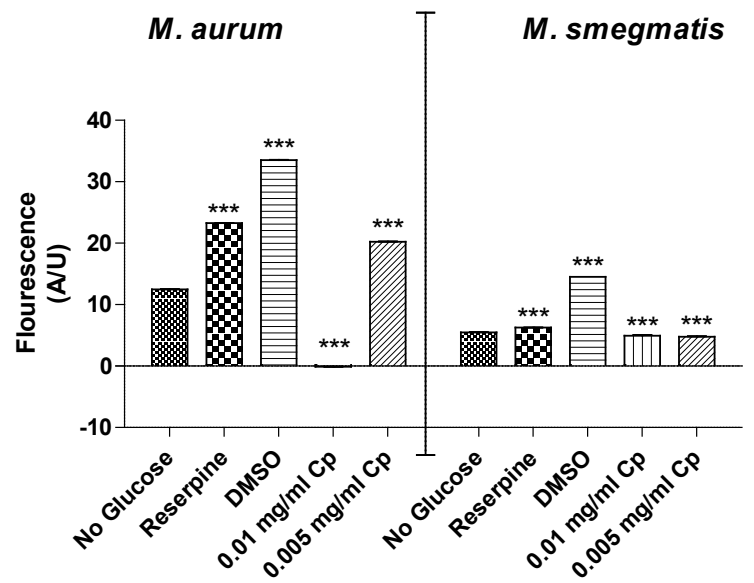

Figure 4: Effects of $C$. platypetalum on drug efflux in mycobacteria. Cells were loaded with ciprofloxacin an incubated for an hour. Cells were centrifuged, supernatant removed and exposed to the various compounds in buffer with glucose. Cells were then centrifuged and the amount ciprofloxacin in the supernatant quantified at excitation and emission wavelengths of $270 \mathrm{~nm}$ and $452 \mathrm{~nm}$ respectively using an RF-1501 Shimadzu spectrofluorimeter. Values are the mean of $+S D$ for $n=2$ for duplicate measurements ${ }^{* * *} P<0.0001,{ }^{* *} P<0.001$ ${ }^{*} \mathrm{P}<0.05$. 
Citation: Magwenzi R, Nyakunu C, Mukanganyama S (2014) The Effect of Selected Combretum Species from Zimbabwe on the Growth and Drug Efflux Systems of Mycobacterium aurum and Mycobacterium smegmatis. J Microbial Biochem Technol S3: 003. doi:10.4172/1948-5948. S3-003

Page 5 of 7

\begin{tabular}{|c|c|c|}
\hline \multicolumn{3}{|c|}{ Zone of inhibition $(\mathrm{mm})$} \\
\hline Plant name & M. smegmatis & M. aurum \\
\hline C. elaeagnoides & na & na \\
\hline C. hereroense & na & na \\
\hline \multirow[t]{3}{*}{ C. imberbe } & $9.5 \mathrm{~mm}$ & na \\
\hline & $\mathrm{MIC}=125 \mu \mathrm{g} / \mathrm{ml}$ & na \\
\hline & $\mathrm{MBC}>1000 \mu \mathrm{g} / \mathrm{ml}$ & \\
\hline \multirow[t]{3}{*}{ C. platypetalum } & na & na \\
\hline & $\mathrm{MIC}=63 \mu \mathrm{g} / \mathrm{ml}$ & $\mathrm{MIC}=125 \mu \mathrm{g} / \mathrm{ml}$ \\
\hline & $\mathrm{MBC}=250 \mu \mathrm{g} / \mathrm{ml}$ & $\mathrm{MBC}=500 \mu \mathrm{g} / \mathrm{ml}$ \\
\hline C. zeyheri & na & na \\
\hline Rifampicin $50 \mu \mathrm{g} / \mathrm{ml}$ & 33 & 21.75 \\
\hline $5 \mu \mathrm{g} / \mathrm{ml}$ & 24 & 10.3 \\
\hline $0.5 \mu \mathrm{g} / \mathrm{ml}$ & 17.5 & na \\
\hline \multirow[t]{2}{*}{$0.1 \mu \mathrm{g} / \mathrm{ml}$} & na & na \\
\hline & $\mathrm{MIC}=<2 \mu \mathrm{g} / \mathrm{ml}$ & $\mathrm{MIC}=<2 \mu \mathrm{g} / \mathrm{ml}$ \\
\hline DMSO & na & na \\
\hline Methanol & na & na \\
\hline
\end{tabular}

na-no activity.

Table 2: Antimycobacterial activity of plant extracts as determined by the agar disc diffusion method.

\begin{tabular}{|c|c|}
\hline Test compound & \% of ciprofloxacin accumulation \\
\hline Combretum hereroense & 277 \\
\hline Combretum imberbe & 274 \\
\hline CCCP & 197 \\
\hline
\end{tabular}

The percentages were calculated by dividing the sample by the control at 60 -minute intervals.

Table 3: Percentage accumulation of ciprofloxacin in $M$. smegmatis due to test compounds

measured using an RF1501 Shimadzu spectrofluorimeter (Shimadzu Corporation, Japan). The plant extracts showed potential in inhibiting the efflux pumps of Mycobacterium smegmatis because of the observed increase in concentration of ciprofloxacin inside the mycobacterial cell. Percentages of accumulated ciprofloxacin due to the test compounds were calculated and are presented in Table 2. The results from percentage calculation indicate that the plant extracts resulted in more ciprofloxacin accumulation than the standard efflux pump inhibitor CCCP. For active motoring of drug efflux in M. smegmatis, Combretum hereroense produced a percentage accumulation of $277.0 \%$, followed by Combretum imberbe with $274.0 \%$, and lastly CCCP, with $197.0 \%$ (Figure 2). End-time monitoring of ciproflaxacin efflux in both species showed that $C$. platypetalum was an effective inhibitor of drug transport (Figure 3). Results on C. imberbe showed that it was an effective inhibitor of drug transport in M. smegmatis with an IC50 of $60 \mu \mathrm{g} / \mathrm{ml}$ (Table 3 and Figure 4).

\section{Discussion}

Current anti-tuberculosis drugs are the products of programmes run 30 to 50 years ago, and inappropriate use of these drugs has led to the appearance of MDR-TB. It is, therefore, critical to have development of new therapies to combat this deadly and prevalent disease. Natural products represent an interesting alternative in the search for new antimycobacterial compounds [15]. The acceptance of traditional medicine as an alternative form of health care and the development of microbial resistance to the available antibiotics has led to the investigation of the antimicrobial activity of Combretum plants in this study. Selection of the plant species was based on their ethno medicinal use in the treatment of symptoms of TB such as chest pains, fever and coughing and a host of other ailments [16,17]. The study,

therefore, was carried out to determine if the selected Combretum plant species had antimycobacterial activity.

The agar disc diffusion method was used to determine if the plant extracts were able to inhibit the growth of mycobacteria. The current study showed that two plant extracts from Combretum imberbe and Combretum platypetalum had antimycobacterial activity against the two species of mycobacteria, with $C$. imberbe having an effect only on M. smegmatis. The other plant extracts, Combretum zeyheri, Combretum hereroense, and Combretum elaeagnoides were not active against both mycobacterial species. Lack of zones of inhibition for the other Combretum species can be linked to lack of potency in the case of C. hereroense, C. elaeagnoides and C. zeyheri or lack of diffusion of the compounds within the agar gel as exemplified here by C. platypetalum. $C$.platypetalum showed growth inhibition only when the extract was tested in broth but not on agar. Evidence for the lack of potency from results of both the agar disc diffusion and broth microdilution method using $M$. aurum was shown. In the agar disc diffusion, there were no zones of inhibition, and in the broth, no antimycobacterial effects were produced for $C$. hereronse, C. elaeagnoides and C. zeyheri. MIC values for M. aurum and M. smegmatis in broth for C. imberbe and C. platypetalum extracts as well as for the standard the antibiotic rifampicin were produced. Sensitivity of $M$. aurum to rifampicin showed that $M$. aurum was not a resistant mycobacterium. However, no antimycobacterial compounds against it were present in the plant extracts under study. The results from the two susceptibility tests used in this study suggest that in practice if one is using plant extracts, it may be useful to test susceptibility both on agar and in broth.

Activity of Combretum imberbe was against M. smegmatis, and its lack of activity against $M$. aurum was unexpected since the two mycobacterium species have similar structures, mainly the length of mycolic acids [3]. Mycobacterium smegmatis shares many features and identical genomic sequences with the pathogenic $M$. tuberculosis and is a potential candidate for developing new TB vaccines [18]. It is also a useful model for screening potential antituberculosis drugs [19]. However, some reports suggest that Mycobacterium aurum may represent a system highly predictive of activity against Mycobacterium tuberculosis because of the comparable drug sensitivity profiles of the two organisms as compared to Mycobacterium smegmatis [3,20,21]. Results from this study, suggest that $M$. smegmatis maybe a better model for $M$. tuberculosis than M. aurum because $M$. aurum was less sensitive to rifampicin than $M$. smegmatis at the same concentration of the drug. The results, therefore, suggest that the plant extracts are not potent against $M$. aurum due to other mechanisms of action that are different from $M$. smegmatis. It can be suggested that probably the structures of these two mycobacterium species are different, with $M$. smegmatis probably having a more permeable cell wall than M. aurum.

Determination of the MIC was performed using the MTT assay and it was shown that $C$. imberbe extract was an inhibitor of growth of M. smegmatis whilst C. platypetalum was a growth inhibitor of both species. An inhibitory effect of the plant extract on these organisms may justify the use of the plant extracts in traditional medicine to treat chest pains and coughs caused by Mycobacterium tuberculosis. The ability of the Combretum extracts to inhibit growth can be attributed to presence of aromatic metabolites, most of which are phenols or their oxygen substituted derivatives. Important subclasses in this group of compounds include phenols, quinones, flavones, flavanoids and tannins [22]. Compounds called combrestatins have also been isolated from Combretum species such as C. molle and C. apiculatum. Combrestatin B5 has been isolated as the main antibacterial compound potent in 
Citation: Magwenzi R, Nyakunu C, Mukanganyama S (2014) The Effect of Selected Combretum Species from Zimbabwe on the Growth and Drug Efflux Systems of Mycobacterium aurum and Mycobacterium smegmatis. J Microbial Biochem Technol S3: 003. doi:10.4172/1948-5948. S3-003

Page 6 of 7

Combretum species [12]. Other isolates from triterpenoids and their glycosides, which have anti-inflammatory activity have been isolated from C. imberbe. Glycoside derivatives of hydroxyimberbic acid from the leaves of $C$. imberbe have antibacterial activity against a few strains of nosocomical organisms and it is possible these could be the ones involved in the antimycobacterial activity against $M$. smegmatis.

Cumulative research efforts into the study of antibiotic resistance mechanisms have implicated efflux pumps as a major underlying factor in intrinsic resistance [23]. The intrinsic and acquired multidrug resistances play an important role in the insurgence of tuberculosis [3]. The accumulation of a drug inside an organism is one of the most frequently used techniques in transport studies. Variations, however, arise in the type of detection compound. Detection usually makes use of radioactive isotopes of common efflux pump substrates [24]. Compounds such as rifampicin and ciprofloxacin are commonly used to quantify accumulated amounts inside the cell [25]. Ciprofloxacin belongs to the fluoroquinolone family of antibiotics. These are potent second line antimycobacterial agents that specifically target DNA gyrase and topoisomerase IV [26].

Ciprofloxacin was used in this study to assess the effects of plant extracts on the drug pumping activity ATP-binding cassette proteins in M. smegmatis and M. aurum. Since it fluoresces, its accumulation was monitored spectrofluorimetrically. The transport assay was performed using two plant inhibitors, C. imberbe, C. platypetalum, C. hereroense, and a standard inhibitor, CCCP. CCCP disperses the proton gradient across the bacterial membrane, thus, affecting the activities of the proton-dependent efflux pumps [27]. As shown in Figures 2-4; the presence of the plant extracts reduced the levels of ciprofloxacin that were effluxed out of the mycobacterial cells resulting in accumulation of the drug inside the cells. Combretum hereroense was a more potent inhibitor resulting in a ciprofloxacin accumulation percentage of $277.0 \%$, whilst for Combretum imberbe it was $274.0 \%$. CCCP, the standard inhibitor caused a ciprofloxacin accumulation of $197.0 \%$. These plant extracts resulted in even much greater ciprofloxacin accumulation than CCCP. Determination of IC50 of Combretum imberbe CCCP was done by incubating the cells with different increasing concentrations of the extract and determining how much of the drug/extract caused a decrease in accumulation of the drug by $50 \%$. IC50 values of $60 \mu \mathrm{g} / \mathrm{ml}$ for C. imberbe and $48 \mu \mathrm{g} / \mathrm{ml}$ for CCCP in the transport of ciprofloxacin indicate the relative potency of this extract in inhibiting the transport process. These results, therefore, suggest that inhibiting efflux pumps could be a mechanism of $C$. imberbe in its role as an antimicrobial agent. Similarly the extract $C$. platypetalum showed inhibition of drug efflux in both species (Figure 4). This study, thus, shows that inhibition of drug efflux should be exploited in the exploration of new targets for drug activity and drug development. This would be of benefit if the extract is combined with drugs such as as tetracyclines, fluoroquinolones, and aminoglycosides (e.g. kanamycin, amikacin) to which the resistance mechanisms would have been established [28].

\section{Conclusion}

Combretum imberbe ethanolic extracts was found to be bacteristatic to Mycobacterium smegmatis and both Combretum imberbe and Combretum hereroense are potential efflux pump inhibitors in Mycobacterium smegmatis. Combretum platypetalum was found to have significant effects on growth and drug efflux in both species. Since Mycobacterium smegmatis and Mycobacterium aurum share many features with the pathogenic $M$. tuberculosis, these pronounced antimycobacterial activities suggest that the Combretum species could be sources of new antimycobacterial therapies with novel or more effective mechanisms of action.

\section{Future prospects for antimycobacterial investigations of the selected Combretum species}

With the great diversity of Combretum species of plants in Zimbabwe, and all over the world, screening of extracts of these plants for antimycobacterial efficacy has much to offer in the search for novel active metabolites that may be effective against Mycobacterium tuberculosis and other infectious Mycobacterium species. After screening, more work needs to be concentrated on the area of identifying the specific compounds that are active against the antimycobacterial species and their specific structures.

For future work in this study, investigations using purified extracts of the compounds will be conducted. The investigations will include experiments that will involve silica gel purification of the ethanol extracted compounds and a repeat of the agar disc experiments with these purified products to determine which of the many compounds are active against the mycobacteria. There is also need to perform mass spectrometry of the resulting active compounds for their complete identification. In light of the above mentioned, repetition of the mechanistic work with the purified compounds will be performed to be sure that the inhibition was related to the putative active compounds. Other recommendations would be to perform the antimycobacterial work with the putative purified active component in $M$. tuberculosis and pursue drug combination investigation upon resistant TB strains.

\section{Declaration of Interest}

The authors report no conflicts of interest. The authors alone are responsible for the content and writing of the paper.

\section{Acknowledgement}

This study was sponsored by the International Science Programs (ISP) through the International Program in the Chemical Sciences (IPICS: ZIM01), Uppsala University, Uppsala, Sweden. Support from the International Foundation for Sciences (IFS), Stockholm, Sweden; Grant Number F/3413-03F and the University of Zimbabwe Research Board (Harare, Zimbabwe) are also acknowledged.

\section{References}

1. Tabuti JR, Kukunda CB, Waako PJ (2010) Medicinal plants used by traditiona medicine practitioners in the treatment of tuberculosis and related ailments in Uganda. J Ethnopharmacol 127: 130-136.

2. Bueno-Sánchez JG, Martínez-Morales JR, Stashenko EE, Ribón W (2009) Anti-tubercular activity of eleven aromatic and medicinal plants occurring in Colombia. Biomedica 29: 51-60.

3. McGaw LJ, Lall N, Meyer JJ, Eloff JN (2008) The potential of South African plants against Mycobacterium infections. J Ethnopharmacol 119: 482-500.

4. du Toit LC, Pillay V, Danckwerts MP (2006) Tuberculosis chemotherapy: current drug delivery approaches. Respir Res 7: 118.

5. WHO (2009) Global tuberculosis report.

6. Pavan RF, Leut CQF, Coelno RG, Coutinho ID, Honda NK, et al. (2009) Evaluation of anti-Mycobacterium tuberculosis activity of Campomanesia adamantium (Myrtaceae) Quim. Nova, 32: 1222-1226.

7. Cowan MM (1999) Plant products as antimicrobial agents. Clin Microbiol Rev 12: $564-582$

8. Ncube NS, Afolayan AJ, Okoh Al, (2008) Assessment techniques of antimicrobial properties of natural compounds of plant origin: current methods and future trends. African Journal of Biotechnology 7: 1797-1806

9. Eloff JN, Katerere DR, McGaw LJ (2008) The biological activity and chemistry of the southern African Combretaceae. J Ethnopharmacol 119: 686-699. 
Citation: Magwenzi R, Nyakunu C, Mukanganyama S (2014) The Effect of Selected Combretum Species from Zimbabwe on the Growth and Drug Efflux Systems of Mycobacterium aurum and Mycobacterium smegmatis. J Microbial Biochem Technol S3: 003. doi:10.4172/1948-5948. S3-003

10. Habtamu Y, Eguale T, Wubete A, Sori T (2010) In vitro antimicrobial activity of selected Ethiopian medicinal plants against some bacteria of veterinary importance. African Journal for Microbiology 4: 1230-1234.

11. Woods-Panzaru S, Nelson D, McCollum G, Ballard LM, Millar BC, et al. (2009) An examination of antibacterial and antifungal properties of constituents described in traditional Ulster cures and remedies. Ulster Med J 78: 13-15

12. Eloff JN, Masoko P (2005) The diversity of antifungal compounds of six South African Terminalia species (Combretaceae) determined by bioautography. African Journal of Biotechnology 4: 1425-1431.

13. Suresh K, Babu S.S, Harisaranraj R (2008) Studies on Invitro Antimicrobia Activity of Ethanol Extract of Rauvolfia tetraphylla. Ethnobotanical Leaflets 12 : 586-590.

14. Michot JM, Van Bambeke F, Mingeot-Leclercq MP, Tulkens PM (2004) Active efflux of ciprofloxacin from J774 macrophages through an MRP-like transporter. Antimicrob Agents Chemother 48: 2673-2682.

15. Jimenez-Arellanes A, Meckes M, Ramirez R, Torres J, Luna-Herrera J (2003) Activity against multidrug-resistant Mycobacterium tuberculosis in Mexican plants used to treat respiratory diseases. Phytother Res 17: 903-908.

16. Angeh JE, Huang X, Sattler I, Swan GE, Dahse H, et al. (2007) Antimicrobial and anti-inflammatory activity of four known and one new triterpenoid from Combretum imberbe (Combretaceae). J Ethnopharmacol 110: 56-60.

17. Fyhrquist $P$ (2007) Traditional medicinal uses and biological activities of some plant extracts of African Combretum Loefl., Terminalia L, and Pteleopsis Engl. Species (Combretaceae). Academic dissertation 1- 183.

18. Thi LN, Maura RB, Férnandez S, Reyes G, Perez JL, et al. (2010) Evaluation of the potential of Mycobacterium smegmatis as vaccine candidate against tuberculosis by in silico and in vivo studies. Vacci Monitor 19: 20-26

19. Altaf M, Miller CH, Bellows DS, O'Toole R (2010) Evaluation of the Mycobacterium smegmatis and BCG models for the discovery of Mycobacterium tuberculosis inhibitors. Tuberculosis (Edinb) 90: 333-337.

20. Piddock LJ, Ricci V (2000) Accumulation of KRM-1648 by Mycobacterium aurum and Mycobacterium tuberculosis. J Antimicrob Chemother 45: 681-684

21. Gupta A, Bhakta S, Kundu S, Gupta M, Srivastava BS, et al. (2009) Fast-growing, non-infectious and intracellularly surviving drug-resistant Mycobacterium aurum: a model for high-throughput antituberculosis drug screening. J Antimicrob Chemother 64: 774-781.

22. Das K, Tiwari RKS, Shristava DK (2010) Technique for evaluation of medicina plant products as antimicrobial agent: current methods and future trends. Journal of Medicinal Plants Research 4: 104-111

23. Pasca MR, Guglierame P, Arcesi F, Bellinzoni M, De Rossi E, et al. (2004) Rv2686c-Rv2687c-Rv2688c, an ABC fluoroquinolone efflux pump in Mycobacterium tuberculosis. Antimicrob Agents Chemother 48: 3175-3178.

24. Ramón-García S, Martín C, De Rossi E, Aínsa JA (2007) Contribution of the Rv2333c efflux pump (the Stp protein) from Mycobacterium tuberculosis to intrinsic antibiotic resistance in Mycobacterium bovis BCG. J Antimicrob Chemother 59: 544-547.

25. Piddock LJ, Williams KJ, Ricci V (2000) Accumulation of rifampicin by Mycobacterium aurum, Mycobacterium smegmatis and Mycobacterium tuberculosis. J Antimicrob Chemother 45: 159-165.

26. Walker RC (1999) The fluoroquinolones. Mayo Clin Proc 74: 1030-1037.

27. Silva PE, Bigi F, Santangelo MP, Romano MI, Martín C, et al. (2001) Characterization of P55, a multidrug efflux pump in Mycobacterium bovis and Mycobacterium tuberculosis. Antimicrob Agents Chemother 45: 800-804.

28. Almeida Da Silva PE, Palomino JC (2011) Molecular basis and mechanisms of drug resistance in Mycobacterium tuberculosis: classical and new drugs. $J$ Antimicrob Chemother 66: 1417-1430.
This article was originally published in a special issue, Bacteria: Biochemical Physiology handled by Editor. Prof. Cheorl-Ho KIM, Sungkyunkwan University, Korea 